\title{
Slowing presentation speed increases illusions of knowledge
}

\author{
Lisa K. Fazio and Elizabeth J. Marsh \\ Duke University, Durham, North Carolina
}

\begin{abstract}
Prior research on false memories has shown that suggestibility is often reduced when the presentation rate is slowed enough to allow monitoring. We examined whether slowing presentation speed would reduce factual errors learned from fictional stories. Would subjects use the extra time to detect the errors in the stories, reducing reproduction of these errors on a later test? Surprisingly, slowing presentation speed increased the production of story errors on a later general knowledge test. Instructing the reader to mark whether each sentence contained an error, however, did decrease suggestibility. Readers appear to passively accept information presented in stories and need a constant reminder to monitor for errors. These results highlight differences between typical episodic false memories and illusions of knowledge (such as learning from fiction). Manipulations that reduce suggestibility for episodic false memories do not always reduce suggestibility for illusions of knowledge.
\end{abstract}

In the modern world, people are inundated by information. Books, movies, newspapers, television, and the Internet are all sources of knowledge. Some sources are purely factual and can be trusted to contain accurate information. Others are fictional, and any information within could possibly be untrue. Critically, it is not always obvious which information in a fictional source is false. Short stories, novels, and movies often mix factual material with imaginary people, places, and events. For example, consider F. Scott Fitzgerald's masterpiece The Great Gatsby. Fitzgerald intermixes real locations in New York City with fictional places such as East Egg and West Egg and moves Biloxi (Mississippi) to Tennessee. Whether or not Fitzgerald intended his errors, statements such as Gatsby's claim to be "a Midwesterner from San Francisco" have the potential to confuse and mislead the reader.

Previous research has supported the idea that reading errors in stories affects performance on later tests. For example, reading errors in a fictional story slows later verification that the statements are false (Gerrig \& Prentice, 1991). It also shifts subjects' self-reported belief in statements such as "mental illnesses are contagious" to be more consistent with story statements (Prentice, Gerrig, \& Bailis, 1997). In our laboratory, we have shown that reading falsehoods in stories reduces the ability to correctly answer general knowledge questions on a later test (Marsh, Meade, \& Roediger, 2003).

In one of our studies, all students read the same story about a job at a planetarium, a story that contained both true and false facts. However, across subjects, the embedded facts were presented in different ways. Whereas some students read the misleading statement "maybe I was supposed to be John Glenn, the first man on the moon," others read a parallel sentence referring to Neil Armstrong. These conditions were compared with a neutral condition, in which subjects read "maybe I was supposed to be the first man on the moon." We were interested in readers' ability to answer related questions on a later general knowledge test (e.g., "Who was the first person to set foot on the moon?"). Reading misinformation led to robust production of the story's errors on the final test, despite a warning against guessing. Importantly, prior reading of misinformation reduced proportion correct below the neutral baseline. That is, after reading misleading facts, students performed worse than if they had read the neutral statements. Readers sometimes relied on the stories even when they had previously known the correct answer.

The effects of learning from fiction are very robust, and manipulations that are typically helpful in reducing false memories fail to reduce suggestibility in this paradigm. For example, preencoding warnings against suggestibility reduce errors in the Deese/Roediger-McDermott (DRM) paradigm for creating false memories for words and in the eyewitness postevent information paradigm (e.g., Gallo, Roediger, \& McDermott, 2001; Greene, Flynn, \& Loftus, 1982). In contrast, readers of fiction continue to produce story errors on a general knowledge test, even if they were warned before reading that the stories were likely to contain errors (Marsh \& Fazio, 2006).

Why do warnings aid subjects in the DRM and eyewitness paradigms, but not in the fiction paradigm? One difference is that, whereas suggestibility in the former paradigms involves confusion of recent episodic memories, the errors in fictional stories often contradict preexperimental knowledge. An examination of the literature on seman-

L.K. Fazio, lkf@duke.edu 
tic memory illusions yields different conclusions about warnings. Even when they are warned that some questions will contain errors, people are willing to answer questions with an incorrect presupposition, such as "How many animals of each kind did Moses take on the Ark?" (Erickson $\&$ Mattson, 1981). It may be particularly difficult to spot errors that are semantically related to the correct answers (Kamas, Reder, \& Ayers, 1996), because the reader fails to notice the discrepancy between what was just read and the information retrieved from semantic memory.

If story readers do not naturally notice discrepancies between story facts and stored knowledge, a global caution about story reliability may not provide a strong enough warning to reduce suggestibility. Instead, we had to require subjects to individually evaluate each sentence of the stories. We created a detection reading condition in which subjects pressed one of two keys (labeled next and error) to proceed to the next sentence. All subjects were warned about the unreliability of the stories, but only the detection subjects had the chance to label each sentence as containing an error. Subjects in the control condition simply pressed the next key after reading each sentence. Suggestibility was reduced (but not eliminated) in the detection condition when subjects were asked to evaluate each story sentence separately for errors (Marsh \& Fazio, 2006).

How did detection instructions change the way readers processed the story and its embedded facts? First, it is noteworthy that readers in the detection condition read more slowly than did control readers. One possibility is that the detection instructions reduced suggestibility because slowed reading allowed additional time for the evaluation and rejection of the misinformation. Results from standard false memory paradigms support this hypothesis. For example, mock eyewitnesses who read a postevent narrative more slowly were more resistant to its misinformation than were fast readers (Tousignant, Hall, \& Loftus, 1986). This result was obtained both when reading speed varied naturally and when it was manipulated via instructions. Similarly, slowing the presentation of the words "bed," "rest," and "dream" reduces false memories for the nonpresented lure "sleep" in the DRM paradigm (McCabe \& Smith, 2002; McDermott \& Watson, 2001).

A second possibility is that the presence and continual use of the error key reminded subjects in the detection condition to monitor for errors throughout the reading period. In contrast, control readers were doing many things at once: reading the sentences and connecting them to each other to create a coherent narrative, remembering the warning, and implementing the warning (which required retrieving information from semantic memory and using it to evaluate the story facts). In short, a global warning imposes a prospective memory load on readers in the control condition. While doing another task-following a story - they must remember to evaluate facts and detect errors, whereas the trial-by-trial reminder in the detection condition relieved the prospective memory load.

The question is whether control subjects' problem was one of divided attention or prospective memory. Is the reader's problem one of juggling tasks (thus making additional time necessary) or instead a difficulty with keeping a goal active (thus making reminders necessary)? The answer will have implications for two different literatures.

Consider first the false memory literature; key is that only one prediction follows from episodic false memory paradigms (that slower presentation decreases suggestibility). Thus, it would be particularly interesting if the results from our fiction paradigm diverged from those observed in the DRM and eyewitness paradigms, since this would highlight the difference between illusions of knowledge and false episodic memories.

Second, in terms of the literature on learning from fiction, both the divided attention and prospective memory hypotheses can be related to Prentice and Gerrig's (1999) dual-process model of how readers learn information from fictional sources. According to their model, readers only systematically evaluate a text if they have both the motivation and the ability to do so. The question here is whether "the ability to do so" depends on time and the capacity to juggle tasks or instead on remembering the task.

The present study assessed whether additional processing time and/or monitoring reminders were key to reducing suggestibility. To control presentation time and alleviate concerns about individual differences in reading times, narratives were presented auditorily, with the sound files digitally altered to be slower or faster than normal speech. All subjects were warned that the stories might contain errors, but only half of the subjects were asked to actively detect errors present in the stories.

If suggestibility is driven by the fact that story readers do not have time to monitor for errors, suggestibility should be reduced in the slow presentation condition. If, however, remembering to monitor for errors is key, detection instructions would then be more beneficial than a change in presentation speed. A third possibility is an interaction whereby detection instructions can only be successfully implemented when the presentation is slow enough to allow monitoring.

\section{METHOD}

\section{Subjects}

A total of 132 Duke undergraduates participated in the experiment for partial fulfillment of a course requirement.

\section{Design}

The experiment had a 3 (fact framing: correct, neutral, misleading) $\times 2$ (question difficulty: easy, hard) $\times 2$ (presentation speed: fast, slow) $\times 2$ (listening instruction: detection, control) mixed design. Listening instruction was the only between-subjects manipulation.

\section{Materials}

Two fictional short stories were taken from Marsh (2004). The stories averaged 1,367 words in length and contained characters, dialogue, and plot. Each story referred to 18 facts from the Nelson and Narens (1980) norms. Half of the facts corresponded to easy questions; on average, $66 \%$ of Nelson and Narens's subjects answered these questions correctly. The remaining 9 facts corresponded to hard questions; on average, $17 \%$ of Nelson and Narens's subjects answered those questions correctly.

In each story, the correct answer was given for one third of the hard and easy critical items (correct items); an incorrect but plausible answer was suggested for another third (misleading items); and the rest of the sentences referred to the same concepts but did not 
suggest a specific term (neutral items). For example, a story about a school science fair contained a reference to the capital of Russia. The neutral sentence stated that "the winner of that contest will get to go to the international science fair in the capital of Russia." The sentence was neutral because it did not mention a particular city. In contrast, the correct version of the sentence read ". . . in Moscow, the capital of Russia," whereas the misleading version read ". . . in St. Petersburg, the capital of Russia." In all cases, we were interested in performance on the final cued recall question, "What is the capital of Russia?" Fact framing was counterbalanced across subjects.

A male speaker digitally recorded all sentences, which he read aloud using his normal rate of speaking. Each sentence was then manipulated into both a fast and a slow version using Audacity software (Audacity Developer Team, 2004). The recording was sped up by $25 \%$ for the fast version and slowed down by $25 \%$ for the slow version. On average, the slow story was read at a rate of $274 \mathrm{msec} /$ syllable (about $6.4 \mathrm{sec} /$ sentence). The fast story was read at a rate of $166 \mathrm{msec} / \mathrm{syllable}$ (about $3.8 \mathrm{sec} / \mathrm{sentence)}$. For each subject, one story was sped up and the other was slowed down; this was counterbalanced across subjects.

The final self-paced test contained 72 questions in cued recall format (e.g., "What is the capital of Russia?"). The questions were tested in a random order; 36 of the questions were critical, and the remainder were fillers.

\section{Procedure}

All subjects were warned that the stories would be fictional ones and that "Authors of fiction often take liberties with certain facts or ideas in order to make the story flow better or be more entertaining. Therefore, some of the information you will hear may be incorrect.'

In Phase 1, all subjects wore headphones to listen to the stories, which were presented sentence by sentence. At the end of each sentence, the word END appeared on the computer screen. Control subjects were instructed to press the next key upon seeing the END cue. Detection subjects were told to press the error key if they noticed anything wrong with the sentence; otherwise, they were to press the next key.

In Phase 2, the filler task, subjects solved visual spatial brain teasers for $5 \mathrm{~min}$.

In Phase 3, the test phase, subjects answered general knowledge questions. They were forewarned that some of the questions would be difficult and that they should not expect to be able to answer all of the questions. Subjects were warned against guessing and were instructed to write I don 't know if they couldn't answer a question.

Finally, all subjects were debriefed as to the experiment's purpose. As part of this debriefing, they read corrected versions of the facts previously read in misleading frames.

\section{RESULTS}

All results were significant at the .05 alpha level unless otherwise noted.

\section{Error Detection During Story Reading}

For subjects in the detection condition, we examined the proportion of critical sentences labeled as contain- ing an error. Subjects detected some of the errors during story reading; they pressed the error key for $23 \%$ of the sentences containing falsehoods. Although low, this was higher than the rates of error presses for correct (13\%) and neutral $(10 \%)$ sentences, yielding a main effect of fact framing $\left[F(2,130)=63.69, M S_{\mathrm{e}}=.02\right]$. Subjects were also more likely to press the error key when reading a hard sentence $(16 \%)$ than when reading an easy sentence $(14 \%)\left[F(1,65)=6.60, M S_{\mathrm{e}}=.01\right]$. As shown in Table 1, this occurred because subjects were more likely to incorrectly press the error key for correct obscure answers than for correct well-known answers.

Importantly, there were no differences as a function of presentation speed: Error detection was equally likely in the two conditions. None of the interactions were significant.

\section{Correct Answers on Final \\ General Knowledge Test}

We next examined the proportion of critical questions answered correctly. As expected, subjects answered a greater proportion of easy questions correctly $(M=.64)$ than of hard questions $(M=.28)\left[F(1,130)=779.53, M S_{\mathrm{e}}=.06\right]$. More importantly, there was a main effect of fact framing $\left[F(2,260)=133.03, M S_{\mathrm{e}}=.07\right]$. Subjects answered more questions correctly after hearing the correct answer in the story $(M=.61)$ than after hearing a neutral sentence $(M=$ .41) $[t(131)=11.95, S E=.02]$. In addition, performance was reduced below the neutral baseline if the misleading version had been presented $(M=.36)[t(131)=4.12, S E=$ .08]. As shown in Figure 1, there was no effect of presentation speed on correct responding. Detection also had no effect, and none of the interactions were significant.

\section{Misinformation Production on Final General Knowledge Test}

Finally, we examined the proportion of questions answered with misinformation. Misinformation was defined as the specific error presented in the stories (i.e., St. Petersburg). Other incorrect answers were not counted as misinformation. The data are shown in Table 2.

Replicating prior work, subjects produced more misinformation after hearing it in a story $(M=.25)$ than after hearing a neutral sentence $(M=.06)$ or the correct answer $(M=.05)$. This was reflected in a main effect of fact framing $\left[F(2,260)=129.85, M S_{\mathrm{e}}=.05\right]$. Subjects were more likely to use misinformation to answer hard questions $(M=.13)$ than to answer easy questions ( $M=$ .11) $\left[F(1,130)=5.695, M S_{\mathrm{e}}=.03\right]$. The interaction between fact framing and question difficulty was significant

Table 1

Proportion of Story Sentences Labeled As Containing an Error, As a Function of Fact Framing, Question Ease, and Presentation Speed

\begin{tabular}{lccccccc}
\hline & \multicolumn{3}{c}{ Easy Questions } & & \multicolumn{3}{c}{ Hard Questions } \\
\cline { 2 - 4 } & Correct & Neutral & Misleading & & Correct & Neutral & Misleading \\
\hline Fast & .09 & .08 & .23 & & .14 & .10 & .23 \\
Slow & .11 & .10 & .24 & & .16 & .10 & .24 \\
$M$ & .10 & .09 & .23 & & .15 & .10 & .24 \\
\hline
\end{tabular}




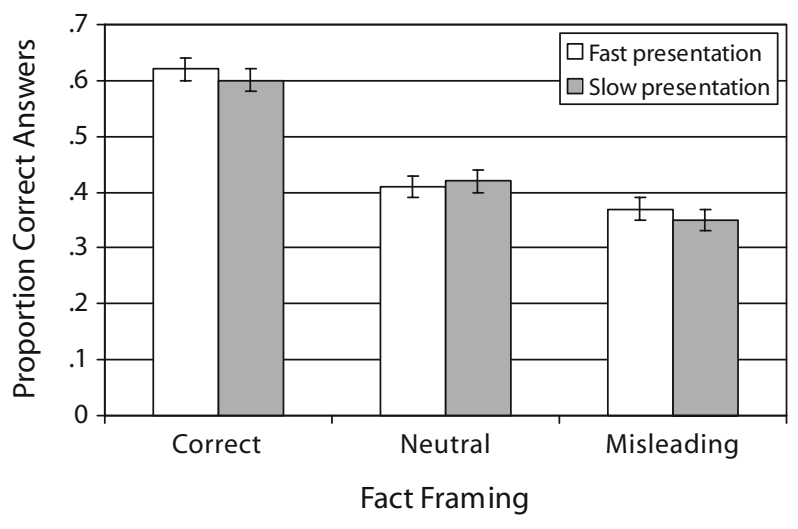

Figure 1. The effect of fact framing on the proportion of final general knowledge questions answered correctly, for fast and slow presentation rates.

$\left[F(2,260)=3.95, M S_{\mathrm{e}}=.03\right]$, with more misinformation being produced for hard questions after subjects had listened to misleading information.

The misinformation effect was reduced in the detection condition. Whereas subjects in the detection condition still produced misinformation $(M=.22)$, they did so at a lower rate than did control subjects $(M=.27)$. In other words, there was an interaction between fact framing and listening instructions $\left[F(2,260)=3.03, M S_{\mathrm{e}}=.05\right]$. Although subjects did not detect all of the errors in the stories, their ability to monitor some of the errors led to reduced suggestibility at test.

Most interesting was a significant interaction between presentation speed and fact framing $[F(2,260)=3.31$, $\left.M S_{\mathrm{e}}=.03\right]$. Contrary to the predictions from episodic false memory paradigms, hearing misinformation presented slowly increased production of those errors on the final general knowledge test (see Figure 2). A greater proportion of the questions were answered with misinformation in the slow condition $(M=.27)$ than in the fast condition $(M=.23)$. No other interactions were significant.

\section{DISCUSSION}

Overall, robust suggestibility effects were observed, even in the detection conditions. To be clear, subjects were able to detect some of the errors during story reading, with a consequent reduction in later suggestibility. This ability to detect errors was not dependent on presentation rate; what was key was the addition of the trial-by-trial monitoring task rather than the amount of time given to do the task. However, even with the constant reminder to monitor, subjects failed to detect many of the errors we would have expected them to catch, on the basis of the Nelson and Narens (1980) norms. This difficulty, combined with the effects of presentation rate on suggestibility, suggests a surprisingly passive reader. When the subjects listened to the stories at a slower rate, they did not use that extra time to actively compare what they were hearing with what they already knew (there was no change in the detection rate). Rather, the slower presentation led to greater suggestibility on the final test.

Two clarifications are warranted. First, it was not the case that the fast presentation speed was too fast to allow processing of the story facts. Subjects in both conditions learned the same amount of correct information from the stories and were equally able to detect story errors. The second clarification involves the Marsh and Fazio (2006) study described earlier, in which detection reduced suggestibility and also slowed reading. In that study, reading time and detection instructions were confounded, precluding analysis of the separate effects of detection and speed. In the present study, detection and speed were manipulated independently, yielding two independent effects: Detection reduced suggestibility, and slow presentation increased it. This pattern suggests that the benefits of detection in the earlier study may have been partially masked by the confounded effects of speed. Although the differences between the studies (i.e., reading vs. listening, differences in reading vs. presentation speeds) make it impossible to compare their results directly, the data suggest that detection reduced suggestibility in Marsh and Fazio's study despite slowed reading, rather than because of it.

Why were the subjects more suggestible to misinformation in the slowed condition, when both conditions showed equal learning of the correct information? Different processes may be involved in learning correct versus misleading facts. Reading correct answers strengthens preexisting associations in semantic memory. The incorrect association, however, is not already stored in semantic memory. In order to produce the misinformation on the final test,

Table 2

Proportion of Final General Knowledge Questions Answered With Misinformation As a Function of Fact Framing, Question Ease, Presentation Speed, and Listening Instructions

\begin{tabular}{|c|c|c|c|c|c|c|}
\hline & \multicolumn{3}{|c|}{ Easy Questions } & \multicolumn{3}{|c|}{ Hard Questions } \\
\hline & Correct & Neutral & Misleading & Correct & Neutral & Misleading \\
\hline \multicolumn{7}{|c|}{ Control Condition } \\
\hline Fast & .02 & .07 & .22 & .04 & .07 & .27 \\
\hline Slow & .05 & .06 & .28 & .06 & .04 & .30 \\
\hline$M$ & .03 & .06 & .25 & .05 & .05 & .29 \\
\hline \multicolumn{7}{|c|}{ Detection Condition } \\
\hline Fast & .05 & .08 & .17 & .06 & .05 & .25 \\
\hline Slow & .06 & .05 & .20 & .06 & .08 & .27 \\
\hline$M$ & .05 & .06 & .18 & .06 & .06 & .26 \\
\hline
\end{tabular}




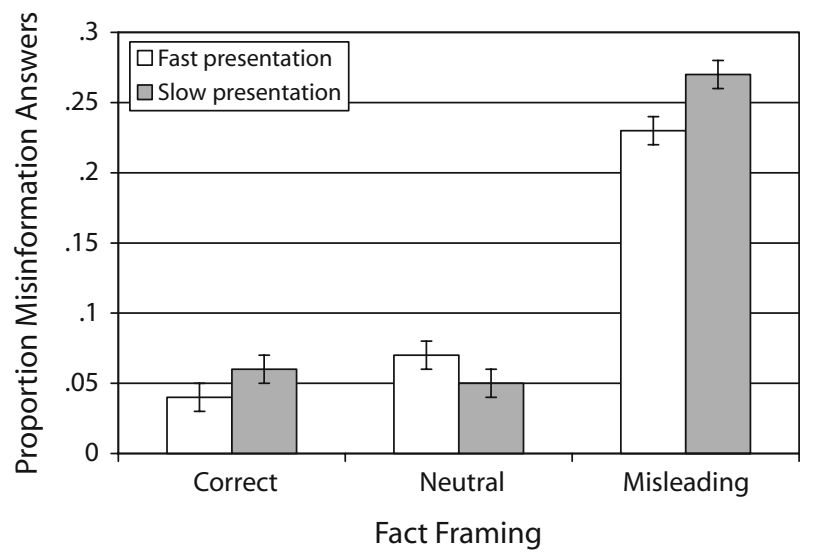

Figure 2. The effect of fact framing on the proportion of final general knowledge questions answered with misinformation, for fast and slow presentation rates.

subjects must form a new episodic memory relating the incorrect answer to the question.

Previous research has dissociated the positive and negative effects of story reading. Marsh, Balota, and Roediger (2005) found that because older adults typically show intact semantic memory abilities, both older and younger adults benefited from hearing correct facts embedded in stories. Because of impaired episodic memory abilities, however, older adults showed less suggestibility than younger adults. Parallel results have occurred with early school-aged children: Whereas age was unrelated to the benefits of story reading, only older children, who typically perform better on episodic memory tasks, produced the misinformation at test (Fazio \& Marsh, 2008).

Applying these ideas to the present data, subjects were able to activate and strengthen preexisting associations in semantic memory at both presentation rates. With additional time, however, they were more likely to encode the misinformation, increasing the likelihood of producing it on the final test. Strikingly, the detection data suggest that readers did not use the extra time to compare what they are reading with what they already know. Prentice and Gerrig's (1999) model states that readers fail to compare information from fictional stories with their own knowledge base unless they have both the motivation and the ability to do so. This experiment suggests that readers" "ability" to monitor the stories for errors depends on an explicit reminder to monitor each sentence.

We end with a comparison of illusions of knowledge and false episodic memories. We classify learning errors from fiction as an illusion of knowledge, since at test subjects incorrectly attribute their misinformation answers to preexperimental knowledge (Marsh et al., 2003). Episodic memory is needed to encode the false facts, but at test subjects do not rely on episodic memory to mentally travel back to the story. Rather, retrieval is familiarity-driven: Prior reading causes the error to come to mind easily at test, and this ease of retrieval is misinterpreted as truth (e.g., Kelley \& Lindsay, 1993). In contrast, when a new word or object is falsely remembered as having occurred in a prior list or video, the mechanisms are likely quite different and may involve problems with source monitoring (Johnson, Hashtroudi, \& Lindsay, 1993). Consequently, the same manipulations can have quite different effects on the two types of errors. We mentioned earlier that preevent warnings are more successful at reducing episodic false memories (Gallo et al., 2001; Greene et al., 1982) than at reducing illusions of truth (e.g., Erickson \& Mattson, 1981; Marsh \& Fazio, 2006). Similarly, both older adults and young children are especially susceptible to episodic false memories (e.g., Balota et al., 1999; Ceci \& Bruck, 1993) but are actually less likely to learn false facts from fiction (Fazio \& Marsh, 2008; Marsh et al., 2005). Our present results regarding presentation rate provide another example, since slowing presentation reduces episodic memory errors (McDermott \& Watson, 2001; Tousignant et al., 1986) but increases an illusion of knowledge.

\section{AUTHOR NOTE}

This research was supported by a collaborative activity award from the James S. McDonnell Foundation. We thank Keith Payne for comments on this research. Correspondence relating to this article may be sent to L. K. Fazio, Duke University, Psychology and Neuroscience, 9 Flowers Drive, Box 90086, Durham, NC 27708-0086 (e-mail: 1kf@duke.edu).

\section{REFERENCES}

Audacity Developer Team (2004). Audacity (Version 1.2.3) [Computer software]. Retrieved January 18, 2005, from audacity.sourceforge.net.

Balota, D. A., Cortese, M. J., DucheK, J. M., Adams, D., Roediger, H. L., III, McDermott, K. B., \& Yerys, B. E. (1999). Veridical and false memories in healthy older adults and in dementia of the Alzheimer's type. Cognitive Neuropsychology, 16, 361-384.

Ceci, S. J., \& Bruck, M. (1993). Suggestibility of the child witness: A historical review and synthesis. Psychological Bulletin, 113, 403-439.

Erickson, T. D., \& Mattson, M. E. (1981). From words to meaning: A semantic illusion. Journal of Verbal Learning \& Verbal Behavior, 20, 540-551.

FAZIO, L. K., \& MARSH, E. J. (2008). Older, not younger, children learn more false facts from stories. Cognition, 106, 1081-1089.

Gallo, D. A., Roediger, H. L., III, \& McDermott, K. B. (2001). Associative false recognition occurs without strategic criterion shifts. Psychonomic Bulletin \& Review, 8, 579-586.

Gerrig, R. J., \& Prentice, D. A. (1991). The representation of fictional information. Psychological Science, 2, 336-340.

Greene, E., Flynn, M. S., \& Loftus, E. F. (1982). Inducing resistance to misleading information. Journal of Verbal Learning \& Verbal Behavior, 21, 207-219.

Johnson, M. K., Hashtroudi, S., \& Lindsay, D. S. (1993). Source monitoring. Psychological Bulletin, 114, 3-28.

Kamas, E. N., Reder, L. M., \& Ayers, M. S. (1996). Partial matching in the Moses illusion: Response bias not sensitivity. Memory \& Cognition, 24, 687-699.

Kelley, C. M., \& Lindsay, D. S. (1993). Remembering mistaken for knowing: Ease of retrieval as a basis for confidence in answers to general knowledge questions. Journal of Memory \& Language, 32 , $1-24$.

Marsh, E. J. (2004). Story stimuli for creating false beliefs about the world. Behavior Research Methods, Instruments, \& Computers, 36, 650-655.

Marsh, E. J., Balota, D. A., \& Roediger, H. L., III (2005). Learning facts from fiction: Effects of healthy aging and early-stage dementia of the Alzheimer type. Neuropsychology, 19, 115-129.

Marsh, E. J., \& FAZIO, L. K. (2006). Learning errors from fiction: Difficulties in reducing reliance on fictional stories. Memory \& Cognition, 34, 1140-1149.

Marsh, E. J., Meade, M. L., \& Roediger, H. L., III (2003). Learning facts from fiction. Journal of Memory \& Language, 49, 519-536. 
McCABE, D. P., \& Smith, A. D. (2002). The effect of warnings on false memories in young and older adults. Memory \& Cognition, 30, 1065-1077.

McDermott, K. B., \& Watson, J. M. (2001). The rise and fall of false recall: The impact of presentation duration. Journal of Memory \& Language, 45, 160-176.

Nelson, T. O., \& Narens, L. (1980). Norms of 300 general-information questions: Accuracy of recall, latency of recall, and feeling-ofknowing ratings. Journal of Verbal Learning \& Verbal Behavior, 19, 338-368.

Prentice, D. A., \& Gerrig, R. J. (1999). Exploring the boundary be- tween fiction and reality. In S. Chaiken \& Y. Trope (Eds.), Dual-process theories in social psychology (pp. 529-546). New York: Guilford.

Prentice, D. A., Gerrig, R. J., \& Bailis, D. S. (1997). What readers bring to the processing of fictional texts. Psychonomic Bulletin \& Review, 4, 416-420.

Tousignant, J. P., Hall, D., \& Loftus, E. F. (1986). Discrepancy detection and vulnerability to misleading postevent information. Memory \& Cognition, 14, 329-338.

(Manuscript received May 24, 2006; revision accepted for publication July 5, 2007.) 